\title{
Color alteration of the paint used for iris painting in ocular prostheses
}

\begin{abstract}
Aline Úrsula Rocha Fernandes(a) Marcelo Coelho Goiato(b) Marcos Antônio Jacó Batista ${ }^{(c)}$ Daniela Micheline dos Santos ${ }^{(d)}$
\end{abstract}

\footnotetext{
(a) Assistant Professor, Department of Prosthodontics, School of Dentistry, National University of Brasília, Brasília, DF, Brazil.

(b) Professor; (d) PhD Student - Department of Dental Materials and Prosthesis, School of Dentistry of Araçatuba, São Paulo State University, Araçatuba, SP, Brazil.

(c) MSc in Material Engineering, School of Chemical Engineering of Lorena (FAENQUIL), Lorena, SP, Brazil.
}

\begin{abstract}
The purpose of this study was to assess color alteration of the paints used for iris painting in artificial eyes. Five disks of heat cured acrylic resin were confectioned by microwave energy for each paint analyzed, in a total of 40 specimens. Each specimen consisted of a colorless acrylic resin disk and another of equal size, of scleral white colored acrylic resin, with the painting interposed between the two disks. The specimens were submitted to an accelerated aging process in a chamber under ultraviolet radiation for 1,008 hours. To assess color variation, a reflective spectrophotometer was used. The results were statistically analyzed by ANOVA and the Tukey test $(\mathrm{p}<0.05)$. All the paints underwent chromatic alteration. The oil paint presented the highest resistance to accelerated aging.
\end{abstract}

Descriptors: Eye color; Artificial eye; Maxillofacial prosthesis; Ultraviolet rays.

\section{Corresponding author:}

Marcelo Coelho Goiato

Departamento de Materiais Odontológicos e Prótese

Faculdade de Odontologia de Araçatuba, UNESP

Rua José Bonifácio, 1193

Araçatuba - SP - Brazil

CEP: 16015-050

E-mail:goiato@foa.unesp.br 


\section{Introduction}

Partial or total loss of the eyes in a human being compromises not only the functional loss of sight, but also his/her self-esteem and social intercourse. An artificial eye is an alloplastic prosthesis with the primordial purpose of restoring a person's identity and re-integrating him/her in society. Due to the great concern about reestablishing facial balance, the art and techniques of artificial eye fabrication date back to remote times, its first manifestations being in the primordial times of human history. ${ }^{1}$

In 1945, Murphey et al. ${ }^{2}$ (1945) were concerned about the color stability of artificial eyes, affirming that it was imperative for all colors to remain free of alterations when exposed to natural or artificial light. It is known that ultraviolet radiation (UV) that reaches the earth's surface represents only $5 \%$ of all light, but it is mainly responsible for the largest part of damage produced when polymers are exposed to intemperate influences.

During the iris painting stage, suitable paints and a reliable technique are required, in which obtainment of the exact color is an arduous task, because one has no control over the color stability of paints after acrylization. ${ }^{3}$

Knowing how color formation occurs, and how important perfect artificial iris characterization is, various authors developed painting techniques, using different paints, such as aquarelle, gouache, oil, automotive and modeling paint; and different surfaces, such as paper, acetate and acrylic resin disks.

With the purpose of obtaining a higher discoloration strength against the action of ultraviolet rays and other environmental factors, various color stability tests were performed, aiming at assessing the chromatic stability of the researched paints, after painting and artificial aging.

In view of the concerns described above, the aim of the present study was to assess the color alterations that occur in paints used for the painting of artificial irises of artificial eyes, when subjected to the action of accelerated aging, as a result of paint, color and accelerated aging period.

\section{Material and Method}

To paint the specimens, four types of paints were used: hydrosoluble gouache, hydrosoluble acrylic, nitrocellulous lacquer-based automotive, and oil paint, as described in Table 1. For all the paints, the colors brown and blue were assessed, as described in Table 2.

For the present study, 40 specimens were confec-

Table 1 - Commercial Brand and Manufacturer of the paints used in

\begin{tabular}{l|l|l}
\hline \multicolumn{1}{c|}{ Paint type } & \multicolumn{1}{|c}{ Brand name } & \multicolumn{1}{c}{ Manufacturer } \\
\hline Hydrosoluble Gouache & $\begin{array}{l}\text { Tinta guache Gato Preto } \\
\text { (Black Cat govache paint) }\end{array}$ & $\begin{array}{l}\text { Tec Screen Indústria de Produtos } \\
\text { Técnicos para Serigrafia Ltda., } \\
\text { Sorocaba, SP, Brazil }\end{array}$ \\
\hline Hydrosoluble Acrylic & $\begin{array}{l}\text { Tinta Acrílica Brilhante } \\
\text { (Glossy Acrylic Paint) }\end{array}$ & $\begin{array}{l}\text { Acrilex Tintas Especiais S.A., } \\
\text { São Bernardo do Campo, SP, Brazil }\end{array}$ \\
\hline $\begin{array}{l}\text { Nitrocellulous lacquer- } \\
\text { based automotive paint }\end{array}$ & Lazzulac Laca Nitrocelulose & $\begin{array}{l}\text { Lazzuril Divisão Automotiva Sherwin- } \\
\text { Williams do Brasil Ind. Com. Ltda., } \\
\text { São Paulo, SP, Brazil }\end{array}$ \\
\hline Oil Paint & Schmincke Mussini & $\begin{array}{l}\text { H. Schmincke \& Company, Erkrath, } \\
\text { Renânia, Germany }\end{array}$ \\
\hline
\end{tabular}

Table 2 - Indication of pigments used in each paint.

\begin{tabular}{l|c|c|c|c}
\hline \multirow{2}{*}{ Colors } & \multicolumn{4}{|c}{ Paints } \\
\cline { 2 - 5 } & Hydrosoluble Gouache & Hydrosoluble Acrylic & Nitrocellulose lacquer automotive & Oil Paint \\
\hline Brown & $\begin{array}{c}\text { Marrom Sépia (sepia brown) } \\
\text { Lot No. }\end{array}$ & Cerâmica (Ceramic) & Marrom café (coffee brown) & Terra de cassel (earth) \\
(BL062701001) & $(3214)$ & (82010001 109) & Azut701) \\
\hline Blue & Azul cobalto (cobalt blue) & Azul celeste (sky blue) & Azul 5258 (blue) & (cobalt blue) \\
Lot No. & (CB062801002) & $(3218)$ & $(91010000594)$ & $(452601)$ \\
\hline
\end{tabular}


tioned using acrylic resin, heat cured by microwave energy. To obtain these specimens, acrylic resin moulds measuring $30 \mathrm{~mm}$ in diameter were confectioned by means of a semi-automatic metallographic embedding press Model PRE-30 S (Arotec, Cotia, SP, Brazil).

The disks were finished with abrasive papers, felt disk, and diamond solution polishing in an automatic polisher, so that they would have an external diameter of $30 \mathrm{~mm}$ and a thickness of $2 \mathrm{~mm}$, as well as uniform and smooth texture. After that, the disks were embedded in a flask for microwaves, using stone plaster type III (Gesso-Rio, Rio de Janeiro, RJ, Brazil).

Ten disks were fabricated of heat cured acrylic resin no.1 for artificial eyes (Artigos Odontológicos Clássico Ltda., São Paulo, SP, Brazil), to obtain specimens pigmented using gouache paint, and 30 disks of colorless acrylic resin, heat cured by microwave energy (Onda Cryl, Artigos Odontológicos Clássico Ltda., São Paulo, SP, Brazil), to obtain specimens pigmented using acrylic, automotive and oil paints. For the different polymers, the monomer Onda Cryl (Artigos Odontológicos Clássico Ltda., São Paulo, SP, Brazil) was used. The resin was manipulated according to the manufacturer's instructions and the molds were filled. After that, the flask was kept in a hydraulic press under 1,200 kgf for approximately 2 hours, and then the disks were polymerized by microwave energy. After the end of the polymerization cycle, the flask was cooled slowly, and then opened to remove the disks.

The disks were finished and polished in an automatic polisher. The thickness and diameter of all disks were gauged with a pachymeter (ME-BA, Zagreb, Yugoslavia), the white disks presenting $30 \mathrm{~mm}$ in diameter and $2 \mathrm{~mm}$ in thickness, and the colorless disks presenting $30 \mathrm{~mm}$ in diameter and $1 \mathrm{~mm}$ in thickness. The thickness values for each disk were defined with the intent of simulating artificial eye fabrication, in which the artificial sclera is more voluminous and the colorless acrylic layer deposited over the painting is approximately $1 \mathrm{~mm}$ thick.

The colors blue and brown were selected for the present study because they represent the basis for painting brown and blue irises, which are frequently found in the buccomaxillofacial rehabilitation clinic. Disk painting was always done in the same period, under the same natural indirect lighting condition, using a no. 0 paint brush ref. 175 (Tigre S.A., São Paulo, SP, Brazil). One of the surfaces of the colorless acrylic disks was painted using acrylic, automotive and oil paints, and the black cardboard disks were painted using gouache paint. Afterwards, the painted cardboard disks were bonded to the resin disks characterized as white sclera, with white adhesive. Three coats of paint were applied to each disk; always waiting for the previous coat to dry completely before applying the next coat. All of the 40 disks, 5 for each of the paints and colors assessed, were left to dry naturally, obtaining complete drying in 24 hours for all paints.

To accelerate oil paint drying, a quantity of Cobalt Dryer (Acrilex Tintas Especiais S.A., São Bernardo do Campo, SP, Brazil) was added, corresponding to $30 \%$ by weight of the amount of oil paint dispensed.

Each specimen consisted of an acrylic resin disk characterized as white sclera, and a colorless acrylic resin disk, with one of the different test paints interposed between them.

All the specimens were finished with polishing devices mounted in a handpiece and abrasive papers numbers 280, 320, 600 and 1200 (Norton, São Paulo, SP, Brazil). Further polishing was performed with a felt disk and $1 / 4$ micron diamond solution (Buehler, Lake Bluff, Illinois, USA) in an automatic polishergrinder and a universal polisher APL-4 (Arotec, Cotia, SP, Brazil), so that they would have an external diameter of $30 \mathrm{~mm}$ and a thickness of $3 \mathrm{~mm}$, and have a uniform and smooth texture.

The accelerated aging tests were performed using the accelerated aging system for non-metallic objects - UVB/condensation (ASTMG 53, American Society for Testing Materials Norma 53, Comexim Matérias Primas Ind. Com. Ltda., São Paulo, SP, Brazil). Due to the dimensions of the specimens, they were exposed to maximum degradation in the aging chamber. All of the specimens were bonded to metal plates measuring $65 \times 233 \mathrm{~mm}$ with adhesive (Araldite hobby, Ciba Especialidades Químicas Ltda., São Paulo, SP, Brazil). The specimens were as- 
sessed initially, and also after periods corresponding to 252,504 and 1,008 hours of accelerated aging by means of spectrophotometry analysis. The chromatic and luminosity alterations were assessed using a reflection spectrophotometer Color-Eye (MacBeth $^{\circledR}$ Kollmorgan Division, Waltham, MA, USA), with the color alterations calculated by the CIE L*a*b* System, established by the Comission Internacionale de I'Eclairage - CIE (International Commission on Illumination).

The data obtained after each aging period were recorded on a specific chart for each paint, color and specimen. Statistical analysis was performed to observe the statistically significant differences in chromatic stability among the four different types of paints, between the two colors, among the accelerated aging periods, and whether there was interaction among these factors. ANOVA and the Tukey test with a significance of $5 \%$ were applied.

\section{Results}

Tables 3 to 6 present the mean values of the derivatives of the specimens for all the studied variables.

All the brown color paints assessed presented good chromatic stability. After 504 hours, the hydrosoluble gouache paint was shown to be less stable. All four blue color paints assessed presented statistically significant differences in all accelerated
Table 3 - Mean Values of the derivatives of the gouache paint specimen for the colors

brown and blue (standard deviation in brackets).

\begin{tabular}{c|c|c|c|c}
\hline \multirow{2}{*}{ Paint } & \multirow{2}{*}{ Color } & \multicolumn{3}{|c}{ Hours of Aging } \\
\cline { 3 - 5 } & & 252 & 504 & 1,008 \\
\hline \multirow{2}{*}{ Gouache } & Brown & $0.726 \mathrm{~A}, \mathrm{a}(0.232)$ & $0.940 \mathrm{~A}, \mathrm{a}(0.167)$ & $1.644 \mathrm{~A}, \mathrm{~b}(0.474)$ \\
\cline { 2 - 5 } & Blue & $1.275 \mathrm{~B}, \mathrm{a}(0.228)$ & $2.224 \mathrm{~B}, \mathrm{~b}(0.152)$ & $2.961 \mathrm{~B}, \mathrm{c}(0.424)$ \\
\hline
\end{tabular}

Means followed by the same upper-case letter in the column and the same lower-case letter in the line did not differ statistically at the significance level of $5 \%(p<0.05)$ by the Tukey Test. the derivatives of the oil paint specimen for the colors brown
Table 4 - Mean Values of and blue (standard deviation in brackets).

\begin{tabular}{c|c|c|c|c}
\hline \multirow{2}{*}{ Paint } & \multirow{2}{*}{ Color } & \multicolumn{3}{|c}{ Hours of Aging } \\
\cline { 3 - 5 } & & 252 & 504 & 1,008 \\
\hline \multirow{2}{*}{ Oil Paint } & Brown & $0.562 \mathrm{~A}, \mathrm{a}(0.235)$ & $0.596 \mathrm{~A}, \mathrm{a}(0.239)$ & $0.786 \mathrm{~A}, \mathrm{a}(0.266)$ \\
\cline { 2 - 5 } & Blue & $2.164 \mathrm{~B}, \mathrm{a}(0.995)$ & $1.601 \mathrm{~B}, \mathrm{ab}(1.117)$ & $1.374 \mathrm{~B}, \mathrm{~b}(0.692)$ \\
\hline
\end{tabular}

Means followed by the same upper-case letter in the column and the same lower-case letter in the line did not differ statistically at the significance level of $5 \%(p<0.05)$ by the Tukey Test.

Table 5 - Mean Values of the derivatives of the acrylic paint specimen for the colors

brown and blue (standard deviation in brackets).

\begin{tabular}{c|c|c|c|c}
\hline \multirow{2}{*}{ Paint } & \multirow{2}{*}{ Color } & \multicolumn{3}{|c}{ Hours of Aging } \\
\cline { 3 - 5 } & & 252 & 504 & 1,008 \\
\hline \multirow{2}{*}{ Acrylic } & Brown & $0.505 \mathrm{~A}, \mathrm{a}(0.174)$ & $0.533 \mathrm{~A}, \mathrm{a}(0.198)$ & $0.881 \mathrm{~A}, \mathrm{a}(0.065)$ \\
\cline { 2 - 5 } & Blue & $4.020 \mathrm{~B}, \mathrm{a}(0.357)$ & $7.038 \mathrm{~B}, \mathrm{~b}(0.714)$ & $9.366 \mathrm{~B}, \mathrm{c}(0.964)$ \\
\hline
\end{tabular}

Means followed by the same upper-case letter in the column and the same lower-case letter in the line did not differ statistically at the significance level of $5 \%(p<0.05)$ by the Tukey Test.

Table 6 - Mean Values of the derivatives of the automotive paint specimen for the colors brown and blue (standard deviation in brackets).

\begin{tabular}{c|c|c|c|c}
\hline \multirow{2}{*}{ Paint } & \multirow{2}{*}{ Color } & \multicolumn{3}{|c}{ Hours of Aging } \\
\cline { 3 - 5 } & & 252 & 504 & 1,008 \\
\hline \multirow{2}{*}{ Automotive } & Brown & $0.183 \mathrm{~A}, \mathrm{a}(0.059)$ & $0.458 \mathrm{~A}, \mathrm{a}(0.04)$ & $0.535 \mathrm{~A}, \mathrm{a}(0.081)$ \\
\cline { 2 - 5 } & Blue & $2.252 \mathrm{~B}, \mathrm{a}(0.124)$ & $4.114 \mathrm{~B}, \mathrm{~b}(0.33)$ & $5.601 \mathrm{~B}, \mathrm{c}(0.618)$ \\
\hline
\end{tabular}

Means followed by the same upper-case letter in the column and the same lower-case letter in the line did not differ statistically at the significance level of $5 \%(p<0.05)$ by the Tukey Test. 
aging periods, showing less resistance to accelerated aging than the brown pigments.

\section{Discussion}

Several authors have suggested a wide variety of techniques for obtaining an artificial iris, ${ }^{4-11}$ such as the use of a printed or photographic reproduction of the patient's natural iris, ${ }^{10,11}$ the use of pre-fabricated irises or prostheses, and a mixture of monomer/ polymer and acrylic pigments. Artificial iris painting is the most delicate step in the confection of ocular prostheses, and it requires method and strict discipline in order for the result to be satisfactory. ${ }^{10,11}$

In the present study, all the paints underwent color variation. The blue acrylic paint presented the least chromatic stability followed by the blue automotive paint. When comparing the brown color paints, the gouache was the least stable one (Tables 3 through 6). Photo-oxidation and hydrolysis are the main paint degradation reactions, and they occur by exposure to sunlight, air, humidity and temperature. These processes are correlated and are accelerated with increase in temperature. The photo-degradation processes cause complete or partial rupture of the polymeric chains, thus leading to a diminished degree of polymerization and loss of properties. ${ }^{12}$

Chromatic alteration of the paints assessed may have been aggravated due to the interaction of their components with acrylic resin, possibly with the residual monomer, since all the paints assessed were polymers and have resins in their compositions.

The blue colored acrylic paint was also assessed by D'Almeida ${ }^{3}$ (2002) and, although it is light-resistant, the author concluded that this pigment presents low coverage power, which causes a significant numerical alteration in the spectrophotometric analysis. The brown colored hydrosoluble acrylic paint presented good chromatic stability (Table 5).

The brown color automotive paint presented excellent stability when submitted to accelerated aging, but this was not the case with the blue color. Although automotive paint is indicated for partial or complete automobile painting, demonstrating that it is highly resistant to intemperate conditions, the blue pigment may have undergone great chromatic alteration due to the chemical instability induced by the interaction with acrylic resin heat cure by microwave energy, or even by the action of the electromagnetic waves generated during polymerization (Table 6).

Wicks et al. ${ }^{13}$ (1999) described the polymeric degradation process. According to these authors, it begins with the absorption of UV light by the polymer, or by another component of the lining, producing a high energy excited state, capable of resulting in homolytic bond scission, generating free radicals. In the next propagation stage, the free radicals formed react with $\mathrm{O}_{2}$, mainly to start degrading the polymer, forming hydroperoxides $(\mathrm{POOH})$ and peroxides (POOP). The products formed are unstable species in the photo-oxidation process which, by action of sunlight and moderate heating, dissociate themselves, producing alcoxi (PO.) and hydroxi (HO.) radicals, making the degradation reactions autocatalytic. These radicals are highly reactive, maintaining the continuity of polymer degradation. The end of the photo-oxidation process may occur by combination of the free radicals generated at the beginning and in propagation, forming a stable product. The addition of stabilizers would be responsible for the autostabilization of the free radicals, minimizing the polymer degradation process. ${ }^{14}$

Ranby, Rabek ${ }^{15}$ (1975) presented a relation between the wavelength and the dissociation energy of different molecules, demonstrating that UV radiation attained at the earth's surface is sufficiently rich in energy to rupture covalent bonds, such as those found in polymers. Only the light absorbed is capable of starting photochemical degradation processes.

Using reflection spectrophotometry, D'Almeida ${ }^{3}$ (2002) assessed the action of accelerated aging on acrylic and automotive paints used for painting artificial irises for prosthetic eyes. The two paints presented similar behaviors when submitted to accelerated aging, the pigments brown and black being those that presented excellent stability, in agreement with the results of the present study.

In the literature researched, no mention was found regarding the alteration of hydrosoluble gouache paint when submitted to ultraviolet radiation, which may occur due to the attack of chemical groupings not very resistant to the action of ultra- 
violet rays. The resin and the possible combinations between resins represent the main component in any paint. The physical-chemical properties of paint, such as applicability, drying, curing, durability, adhesion, chemical and mechanical resistance, flexibility and hardness are basically governed by the nature of the resins. Some minor variations of these properties may be achieved by modifying other components in the formulation, but the system of resins has the greatest influence. The durability of this system of resins also works as a factor limiting the stability of the paint, and deserves special attention for obtaining a product with good performance.

In the present study, the brown color demonstrated higher chromatic stability than the blue color when submitted to accelerated aging, in all the paints assessed. Theoretically, light colors reflect the radiation incident on them, while dark colors absorb it. Thus, dark colors should present greater instability when submitted to ultraviolet radiation, by the greater absorption and larger quantity of electromagnetic rays influencing their behavior. Dark pigments demonstrated higher resistance to the degrading effects of ultraviolet radiation, possibly due to the formation of more stable chemical bonds, not subject to breaking in short periods of aging. Another important factor is the possible incorporation of impurities during the obtainment of paints. Some impurities absorb light and make polymers sensitive to UV radiation, such as residues of catalyzers, products of the oxidation itself, and substances added during the manufacturing process, which probably occurred with the blue pigment. Polymers that

\section{References}

1. Bruce GM. The ancient origins of artificial eyes. Ann Hist Med. 1940;2:10-4.

2. Murphey PJ, Pitton RD, Schlossberg L, Harris LW. The development of acrylic eye prosthesis at the National Naval Medical Center. J Am Dent Assoc. 1945;32(19):1227-44.

3. D'Almeida NF. Contribuição ao estudo da estabilidade cromática em prótese ocular [Tese de Doutorado em Odontologia, Área de Concentração em Prótese Buco-Maxilo-Facial]. São José dos Campos: Faculdade de Odontologia de São José dos Campos, Universidade Estadual Paulista; 2002. have basic groups of UV absorbers in their structure are susceptible to photochemical degradation.

Therefore, after analyzing the results and discussing them in view of the results found in the related literature, the authors of the present study indicate the use of oil paint in the colors brown and blue for clinical fabrication of artificial eyes due to its more stable behavior when submitted to ultraviolet radiation. Clinically, artificial eyes with irises pigmented in light colors (blue) should be changed more frequently in order to prevent esthetic alterations due to paint discoloring.

\section{Conclusion}

In view of the results obtained with the proposed methodology, it was concluded that:

- Hydrosoluble acrylic, hydrosoluble gouache, nitrocellulose-based automotive and oil paints present numerical chromatic alteration when submitted to accelerated aging by ultraviolet radiation and water condensation.

- The brown color presented statistically significant higher chromatic stability when compared with the blue color, irrespective of the paint and period of aging assessed.

- The oil paint has excellent and significant chromatic stability for use in painting artificial irises for prosthetic eyes polymerized by microwave energy, irrespective of color, when compared with the other paints assessed.

- Artificial eyes fabricated with dark pigments have a longer lifetime use.

4. Dyer NA. The artificial eye. Aust J Ophthalmol. 1980;8:3257.

5. Allen L, Webster HE. Modified impression method of artificial eye fitting. Am J Ophthalmol. 1969;67:189-218.

6. Taicher S, Steinberg HM, Tubiana I, Sela M. Modified stockeye ocular prosthesis. J Prosthet Dent. 1985;54:95-8.

7. Benson P. The fitting and fabrication of a custom resin artificial eye. J Prosthet Dent. 1977;38:532-8.

8. Sykes LM. Custom made ocular prostheses: a clinical report. J Prosthet Dent. 1996;75:1-3. 
- Color alteration of the paint used for iris painting in ocular prostheses

9. Couillard P, Schaaf NG. Fabrication of the ocular portion of an orbital prosthesis. J Prosthet Dent. 1976;35:478-81.

10. Meissner EG. Propiedades y ventajas de una prótesis ocular de material plástico (La teoría del color de Oswald y su aplicación en oftalmoprótesis). Rev Odontol Concepción. 1960;7(3):847.

11. Artopoulou II, Montgomery PC, Wesley PJ, Lemon JC. Digital imaging in the fabrication of ocular prostheses. J Prosthet Dent. 2006;95:327-30.

12. Martínez de las Marías P. Química y Física de Los Altos Polímeros y Materias Plasticas. Madrid: Alhambra; 1972.
13. Wicks ZW, Jones FN, Pappas SP. Educational Series - Exterior Durability: I. Journal of Coatings Technology. 1999;71:535.

14. Bauer DR, Gerlock JL, Mielewski DF. Photostabilization and Photodegradation in Organic Coatings Containing a Hindered Amine Light Stabilizer. Part VII. HALS Effectiveness in Acrylic Melamine Coatings Having Different Free Radical Formation Rates. Polym Degrad Stab. 1992;36:9-15.

15. Ranby BG, Rabek JF. Photodegradation, photo-oxidation, and photostabilization of polymers: principles and applications. London; New York: Wiley; 1975. 